\title{
CLINICAL SIGNIFICANCE OF CoQ10 IN PERIODONTAL HEALTH
}

\author{
Rajiv Saini ${ }^{1}$
}

${ }^{1}$ Associate Professor, Department of Periodontology, Pravara Institute of Medical Sciences.

\section{ABSTRACT}

\section{BACKGROUND}

Periodontitis is a destructive inflammatory disease of the supporting tissues of the teeth and is caused either by specific microorganisms or by a group of specific microorganisms, resulting in progressive destruction of periodontal ligament and alveolar bone with periodontal pocket formation, gingival recession, or both. Periodontitis is a destructive inflammatory disease of the supporting tissues of the teeth and is caused either by specific microorganisms or by a group of specific microorganisms, resulting in progressive destruction of periodontal ligament and alveolar bone with periodontal pocket formation, gingival recession, or both. The present study confirmed that long-term regular intake of nutritional dietary supplement of CoQ10 is more beneficial in nonsurgical treatment outcome of periodontal disease.

\section{KEYWORDS}

CoQ10, Periodontitis, Phase 1 Therapy, Inflammation.

HOW TO CITE THIS ARTICLE: Saini R. Clinical significance of Coq10 in periodontal health. J. Evolution Med. Dent. Sci. 2017;6(60): 4439-4440, DOI: $10.14260 / \mathrm{Jemds} / 2017 / 959$

\section{BACKGROUND}

Oral cavity is an open growth system with an uninterrupted introduction and removal of microbes and their nutrients. It offers diverse habitats where in different species of microorganisms can prosper. The primary requisite for any group of microbes to flourish in a niche is their ability to adhere to the tooth surfaces and multiply in shielded environments like periodontal pockets and tooth crevices.[1] Biofilms have been found to be involved in a wide variety of microbial infections (by one estimate $80 \%$ of all infections). These include dental caries, periodontal disease, otitis media, musculoskeletal infections, necrotising fasciitis, biliary tract infection, osteomyelitis, bacterial prostatitis, native valve endocarditis, melioidosis, cystic fibrosis pneumonia and periimplantitis. Salient features of these infections are persistence and chronicity.[2] Biofilms protect bacteria living within their structures and thereby provide an advantage over free-floating (planktonic) bacteria. The slimy extracellular matrix produced by biofilm bacteria encloses the microbial community and protects it from the surrounding environment, including attacks from chemotherapeutic agents. Chemotherapeutic agents have difficulty penetrating the polysaccharide matrix to reach and affect the microorganisms. ${ }^{[3,4,5]}$ Currently, oral biofilm control is primarily accomplished through the use of dentifrice containing compounds such as detergents, abrasives and antimicrobials, which achieve their effects in conjunction with mechanical tooth brushing.[6] If biofilm accumulation and growth can be reduced and its re-aggregation discouraged, this will result in improved gingival health.[7]

Financial or Other, Competing Interest: None.

Submission 21-06-2017, Peer Review 14-07-2017,

Acceptance 21-07-2017, Published 27-07-2017.

Corresponding Author:

Dr. Rajiv Saini,

Department of Periodontology,

PIMS, LONI,

Rahata, Ahmednagar,

Maharashtra.

E-mail: drperiodontist@yahoo.co.in,drrajivsaini@gmail.com

DOI: $10.14260 /$ jemds $/ 2017 / 959$

(c) (i) $\risingdotseq$
Conversely, ineffective plaque control is directly implicated in gingival inflammation and eventually in destructive chronic periodontitis.[8]

Recently introduction of additional supplementation of enzymes, antioxidants, vitamins, nutrition and probiotics along with conventional oral hygiene were observed and studied. The one of the most promising component is supplementing of Co-enzyme Q10 (CoQ10) in boosting the optimal periodontal health. Coenzyme Q10 (CoQ10) is a substance that helps convert food into energy. CoQ10 is found in almost every cell in the body, and it is a powerful antioxidant. Antioxidants fight damaging particles in the body known as free radicals, which damage cell membranes, tamper with DNA, and even cause cell death. Antioxidants, such as CoQ10, can neutralise free radicals and may reduce or even help prevent some of the damage they cause.

A study evaluated the clinical and microbiological effects on chronic periodontitis patients with complete oral prophylaxis (Scaling and Root Planing) followed by dietary supplement of CoQ10 (Oxyfresh, USA) for 4 months of time period. The study selected the 25 subjects after their informed written consent with chronic periodontitis with a pre-fixed inclusion and exclusion criteria as illustrated in Table 1. After enrolment of the subjects in the study, Phase 1 therapy (Complete scaling and root planing) was done by similar EMS ultrasonic scaler to all the subjects enrolled in the study. Subjects were advised to brush twice daily 5 minutes with modified bass method technique (Technique demonstrated to each subject) and similar medium bristle tooth brushes were provided to each of the enrolled subject during the study course to maintain standardisation. The subjects were further advised for a mouth rinse twice daily ( 5 $\mathrm{mL}$ in quantity for 1 minute). Subjects with respective groups were further provided with dietary supplement of CoQ10 with instructions for the regular consumption for the same with regime (TDS $\times 4$ months). By applying Student's Paired ' $\mathrm{t}$ ' test, there was a significant decreased from baseline to 4 months for mean values of clinical and microbiological parameters where $\mathrm{p}<0.05$. Clinical observations of study confirmed that there was $10.22 \%, 13.39 \%, 17.38 \%$ and 9.79\% percentage decrease of Gingival Index (GI), Plaque 
Index (PI), Clinical Attachment Level (CAL) and Probing Depth (PD) from baseline to $4^{\text {th }}$ month respectively. The microbiological parameters Aggregatibacter actinomycetemcomitans (Aa), Fusobacterium nucleatum (Fn), Porphyromonas gingivalis (Pg) and Prevotella intermedia (Pi) were recorded. There was $24.12 \%, 17.94 \%$, $19.68 \%$ and $21.31 \%$ percentage decrease of $\mathrm{Aa}, \mathrm{Fn}, \mathrm{Pg}$ and $\mathrm{Pi}$ from baseline to $4^{\text {th }}$ month. The results of the study markedly showed the efficiency of CoQ10 and its potential benefits in periodontitis patients. Previously done clinical studies with oral administration of CoQ10 to patients with periodontal disease were similar to our study in results. Results of earlier studies also supported that oral administration of CoQ10 increases the concentration of CoQ10 in the diseased gingiva and effectively suppresses advanced periodontal inflammation and periodontal microorganisms. $[9,10,11]$ The recently conducted study also supported that CoQ10 supplementation along with scaling and root planing can prevent periodontitis by reducing gingival inflammation.[12]

These findings suggest that there were significant clinical and microbiological benefits in supplementing nutritional supplement of CoQ10 with professional prophylaxis.

\section{Exclusion Criteria}

1. Presence of any systemic neurological disorders (e.g., epilepsy or schizophrenia).

2. Presence of a disease with possible effects on the immune system (e.g., chronic infections or cancer).

3. Patients who have received antibiotics or NSAIDS (like Ibuprofen) in past 9-11 weeks.

4. Patients who have received periodontal treatment in past 6 months.

5. Pregnant and lactating mothers.

6. Patients with artificial prosthesis.

7. Patients who smoke or consume tobacco in any form.

8. Patients suffering with diabetes, arthritis or any type of heart disease (MI, CHD, etc.).

9. Female patients using intrauterine birth control devices or birth control pills.

10. Obese individuals ( $30 \&$ above range as per WHO BMI cut-off for weight categories for Asians).

11. Subjects not willing to participate in the study.

\section{REFERENCES}

[1] Chandki R, Banthia P, Banthia R. Biofilms: a microbial home. J Indian Soc Periodontol 2011;15(2):111-4.

[2] Socransky SS, Haffajee AD. Dental biofilms: difficult therapeutic targets. Periodontol 2000 2002;28(1):1255.

[3] Costerton JW, Stewart PS, Greenberg EP. Bacterial biofilms: a common cause of persistent infections. Science 1999;284(5418):1318-22.

[4] Brown MR, Gilbert P. Sensitivity of biofilms to antimicrobial agents. J Appl Bacteriol 1993;(Suppl 74): 87S-97S.

[5] Gilbert P, Das J, Foley L. Biofilm susceptibility to antimicrobials. Adv Dent Res 1997;11(1):160-7.

[6] Sanz M, Serrano J, Iniesta M, et al. Antiplaque and antigingivitis toothpastes. In: van Loveren C. edr. Toothpastes. Monographs in oral science. Basel: Karger International 2013;23:27-44.

[7] Theilade E, Wright WH, Jensen SB, et al. Experimental gingivitis in man. II. A longitudinal clinical and bacteriological investigation. J Periodontal Res 1966;1(1):1-13.

[8] Axelsson P, Lindhe J. The significance of maintenance care in the treatment of periodontal disease. J Clin Periodontol 1981;8(4):281-94.

[9] Wilkinson EG, Arnold RM, Folkers $\mathrm{K}$, et al. Bioenergetics in clinical medicine. II. Adjunctive treatment with coenzyme $\mathrm{Q}$ in periodontal treatment. Res Commun Chem Pathhol Pharmacol 1975;12(1):111-23.

[10] Shizukuishi S, Hanioka T, Tsunemitsu A, et al. Clinical effect of coenzyme 10 on periodontal disease: evaluation of oxygen utilization in gingiva by tissue reflectance spectrophotometry. In: Shizukuishi S, Hanioka T, Tsunemitsu A. eds. Biomedical and clinical aspects of Coenzyme Q. Amsterdam: Elsevier 1986;5:359-68.

[11] McRee JT, Hanioka T, Shizukuishi S, et al. Therapy with Coenzyme Q10 for patients with periodontal disease. 1. Effect of Coenzyme Q10 on subgingival microorganisms. J Dent Health 1993;43:659-66.

[12] Manthena S, Rao MV, Penubolu LP, et al. Effectiveness of CoQ10 oral supplements as an adjunct to scaling and root planing in improving periodontal health. Journal of Clinical and Diagnostic Research 2015;9(8):ZC26-ZC8. 